\title{
The 10th International Symposium on the Biosafety of Genetically Modified Organisms (ISBGMO), Wellington, New Zealand, November 2008*
}

\author{
Jeremy SWEET \\ Sweet Environmental Consultants, 6 Green Street, Cambridge CB24 5JA, UK
}

The Symposium consisted of eight sessions of oral presentations as well as various workshops and poster sessions. This report reviews the presentations in the following sessions and discusses the main conclusions and issues arising from each session:

Session 1: Biosafety - experience and results

Session 2: Introgression, invasion and fitness

Session 3: Biotic and abiotic stress resistance

Session 4: GM animals

Session 5: Effects of GM crops on soil ecosystems

Session 7: Biocontainment methods

Session 8: Post market environmental monitoring

Abstracts of the presentations in these sessions are available at: http://www.isbgmo.info/assets_/isbgmo_ symposium_handbook.pdf

\section{Session 1: Biosafety - experience and results}

\section{Sally L. MCCAMMON}

Biotechnology Regulatory Services, Animal and Plant Health Inspection Service, United States Department of Agriculture, Riverdale, Maryland, 20737, USA

Presentations:

1. Risk Assessment: Challenges of New Biotech Products. Martina Newell-McGloughlin (USA)

2. GMO risk assessments: lessons learnt from seven years of regulatory experience in Australia. Elizabeth Flynn (Australia)

3. Meta-analysis of the effects of Bt crops. Michelle Marvier (USA)

\footnotetext{
* Reports and reviews of Sessions of Oral presentations written by the chairpersons and/or coordinators of the sessions and compiled and edited by Jeremy Sweet (Chairman of the Scientific Programme Committee). The reviews reflect the views and opinions of the authors of the reports and are not necessarily the views of the presenters in the sessions.
}

4. Current genetically-modified plants appear to have no significant impact on the soil environment - Will this be true of future GMOs? Guenther Stotsky (USA)

5. GM plant development and Research in Thailand. Boonyanath Nathwong (Thailand)

6. Regulatory considerations and commercialisation of minor crops: GM Carnations. Steve Chandler (Australia)

7. The safety of GMOs in the research agenda of the knowledge-based bio-economy. Ioannis Economidis (EC)

\section{INTRODUCTION}

The first generation of biotechnology crops, containing primarily single traits for insect resistance and/or herbicide tolerance, has been grown extensively for over fifteen years after evaluation in many regulatory systems, on several continents. This has been supported by multiple biosafety studies to assure an understanding of the interaction of these plants with the environment. During this time, various regulatory systems and risk assessment have been evolving as experience accrued. However, challenges continue to arise for risk assessors as many 
new types of products, including animal products, are developed using advanced genetic engineering techniques. Governmental and private product developers have to contend with varying regulatory approaches depending upon legislative mandates between different countries and the need for refinement of assessment strategies to accommodate new types of products. Session I of the 10th International Symposium on the Biosafety of Genetically Modified Organisms (ISBGMO) continued the exploration of biosafety research and its link to risk assessment (and regulation). This paper is a synthesis of the some of the main ideas presented in Session I.

\section{Experience and biosafety research}

Economies are based either in part or in whole upon their biological resources and this dependency is projected to increase - for food, for health, for the environment and for the renewable resources that humans need to live in a sustainable, integrated manner. Ioannis Economidis considered that the use of genetic engineering is being seen more and more as one of many tools being applied to address environmental problems and opportunities that have come to the forefront of social need - from pest and disease resistance in plants and animals, to renewable energy resources, to reduction in animal pollutants and to reduction of vectors of human and animal diseases. Such a broadening range of plant products include, for example, pharmaceuticals from transgenic banana, varied oils in plants, and higher digestibility in forage plants. Martina Newell-McGloughlin indicated that the new technologies include the tools of synthetic biology, RNA interference, and applications arising from the understandings of epigenetics, transgenomics, and paramutation. Boonyanath Nathwong said that developing countries are seeing the application of genetic engineering as a means to solve problems unmanageable by traditional breeding techniques such as virus resistant papaya, chilli and tomato as well as exportable products such as colorenhanced and long-lived orchids which can contribute positively to their economies. Without taking advantage of these technologies appropriately, trade deficits continue to be intractable problems.

Biosafety research on transgenic organisms is now being seen as part of the support needed to achieve the larger social policy objectives with minimal and/or manageable unwanted associated effects. To adapt to the changing scientific and product landscape, governments and risk assessors rely on the scientific information produced by biosafety researchers and others to provide information for science-based decisions. Biosafety research on transgenic organisms can provide the information to accomplish these tasks. This is done in conjunction with basic research targeted toward understanding unmodified organisms for a variety of purposes, which can be used to compare with the behavior of transgenic organisms.

Biosafety research funded by governments is complementary to regulatory requirements. Economidis considered that such research should be relevant to risk assessment and useful for risk assessors. One standard to which biosafety research is held is whether any issues have been resolved as a result of such research. Over the years, unfortunately, in some areas the lack of such resolution has led to the reduction in funding. To be useful, the results of the research must be helpful in decision-making about the products of modern biotechnology. This session highlighted several areas in which resolution of complex issues has been obtained.

Of great interest to biosafety researchers, risk assessors, and the public has been the incorporation of insecticidal genes from the microbe, Bacillus thuringiensis (Bt), into plants for resistance to coleopteran and lepidopteran insect pests, through expression of toxins whose only known targets are these insects. As a novel approach to insect pest control, concern was raised over potential effects on other organisms that were not the target of the toxin through their association with the plants, primarily through exposure to the insect toxin through other routes besides herbivory - predators of target herbivores, vectors and consumers of pollen, or microbes in the soil.

After over fifteen years of use of various products developed with the Bt insect-resistance traits, multiple studies of potential impacts on non-target organisms looking at different functional groups have been analyzed through meta-analyses of several types of field and laboratory studies. Michelle Marvier described the analyses of data from field experiments in maize and cotton which indicate that there generally has been minimal or no significant impact on invertebrate organisms in the environment. Invertebrates are generally more abundant in $\mathrm{Bt}$ crop fields but less abundant than in non-pesticide treated non-transgenic fields. This was when compared with appropriate controls of pesticide treatment (e.g. pyrethrin) and/or untreated non-Bt plantings. These analyses included a comparison of over 25 studies of the effect of Bt on bees in which no direct effect of the toxin could be demonstrated. These results also confirm the tiered testing of these Bt crops and indicate that the tiered approach is a good one.

Those cases in which impact was found were expected. It was no surprise that predators of herbivores that are sensitive to Bt plants were affected, not by the toxin per se but by the reduction in their food source. The findings reported by Marvier verify the assessments of regulators and risk assessors who have evaluated these products for commercial release. It also has demonstrated that wellperformed science can address the issues raised by risk assessors. 
Guenther Stotsky discussed the conclusions that have been reached regarding the potential for non-target effects of the Bt toxin in soil. The pro-toxin can be exuded by certain plant roots - corn, rice, and potato, but not canola, tobacco, or cotton. It can bind to certain clay and humic acid soils and can remain without degradation for almost a year. The absorption to soil particles prevents degradation and the molecule accumulates in the soil as a result. The plant cultivar or transformation event is not important. In addition, Bt biomass decomposes much more slowly than non-Bt corn, rice or canola, and this is not correlated to a higher lignin content. Whatever the processes involved, there is no effect on the soil biota, microbiota and processes including on bacteria, fungi, algae, earthworms, nematodes and protozoa.

Another example, that helped to resolve concerns over unexpected variation coming through the process of transgenesis was mentioned Martina NewellMcGloughlin. This involved protein profiling studies in wheat and potato that have shown greater variation between conventional cultivars, especially in regard to geography, than between transgenic cultivars and their progenitors.

The weight of evidence or use of multiple sources of data and information substantially increases the appropriate analyses and conclusions by risk assessors. The metaanalyses of Bt studies by Michelle Marvier demonstrated the value and application of meta-analysis for increasing the confidence in the conclusions coming from multiple studies in the literature. It also emphasized the rigor necessary to achieve resolution of issues raised by the use organisms in the environment. Scientific studies will be most valuable if rigorous statistical methods are used and if the actual data and experimental design are reported in the literature so that others may repeat the analysis performed on the data. For real value scientific studies are most useful if they meet a certain level of quality including appropriate replication and sample size. In addition the use of appropriate controls is important in establishing the applicability and relevance of a study. Use of such consolidated information and data can answer biosafety questions with greater certainty. It also helps avoid the problem of individual papers being taken out of context and reduces the potential for single scientific papers to overly sway public opinion which can be counter productive in meeting mandates for assuring product safety.

\section{Experience, risk assessment and regulation}

Regulatory systems vary widely from country to country as agricultural, political and legal systems vary. These systems are also evolving as experience from scientific information and practical implementation as well as social acceptance is gained. Elizabeth Flynn from the Office of the Gene Technology Regulator described how Australia's system for genetically engineered organisms went from a voluntary system to a mandatory system that applied to all transgenic organisms with the passage of the Gene Technology Act in 2000. The Act addressed issues identified in the previous system, coordination across government agencies, and provided accountabilty and openness to the public to assure that any risks that might occur with transgenic organisms were identified and managed. The current system covers both intentional and non-intentional release applications of the technology and assumes stepwise development of products in general - from the laboratory to confined field testing to unconfined release. Assessments are performed case-by-case. Transparency which allows public review and input of the risk assessment and risk management plans has been a cornerstone of the success of the current system which has allowed licensing of 10 commercial scale releases of cotton, canola, carnation and cholera vaccine. Determined and consistent application of risk assessment principles and methodologies, coupled with experience, has led to two revisions in 2005 and 2007 of the risk assessment framework first published in 2001. Risk assessment processes include hazard identification, risk identification of plausible causal pathways, and risk characterization. These framework revisions have been based upon experience and lessons learned with actual assessments of transgenic organisms to the generally accepted model of risk analysis. The Australian story illustrates that regulatory systems can evolve as social need, experience and new products and situations arise.

Boonyanath Nathwong pointed out that associated risk assessment processes can be, and are being, refined to address transgenic products appropriately in different countries. In each country, risk assessment is normally carried out under the auspices of a legal framework which mandates protection of certain valued aspects of the environment. For many of the regulatory systems in place today, experience was gained from the first generation of traits in four basic commodity crops - maize, cotton, soybean and canola. Many countries anticipated that they would be developing their own versions of these crops or would be developing their own plant products. Thus, regulatory and risk assessment systems were put in place to deal with plant products with enhanced capability for surviving biotic stress. There are now new challenges to regulatory systems and environmental risk assessors that include a plethora of new kinds of products, new applications of technologies and stacking of genes.

Boonyanath Nathwong and Steve Chandler also indicated that there are differences between countries as to whether legal mandates and regulatory systems have been established. The development and implementation of such systems has occurred at varying rates. In some 
cases regulatory systems are struggling to address the first generation of products. Disparities between timing of delivery of research to address national needs, biosafety research and establishment of regulatory systems in different countries has led to delay, sometimes for years, before basic testing in the environment can be done to address identifiable and previously insoluble problems of pest and disease.

The session highlighted some of the issues, if resolved, would make regulatory systems around the globe more effective and efficient. For example, field testing is a critical component for developers to select new, improved, safe plant lines as well as to demonstrate to risk assessors that new plant lines behave as predicted. Field testing also provides the venue for research on particular biosafety questions. However, the requirements for field testing vary considerably between countries and are prohibitive in some cases. Sometimes, risk assessment for field testing may focus on confinement or, in other cases, on the issues of unconfined release necessitating a fullblown environmental assessment.

Some of the promise of biotechnology has been overshadowed by the increasing timeframes that it takes to move products through national regulatory systems. For instance it can take $7-10$ years to move a product through the US system. The same product may have to meet multiple varying requirements under different regulatory regimes internationally. Data and information requirements between each of these systems can differ. Steve Chandler demonstrated how meeting these requirements for a global product such as cut flowers can be daunting. This is compounded when there is lack of information from regulators as to the risk being addressed by any particular requirement. Increased clarity regarding purpose of data and information requirements would enhance the product assessment process and safety.

\section{Conclusions}

Investment of public funds in research, including biosafety research, is made to provide the knowledge important for commercial development, human and animal health, the environment and the economy. Ioannis Economidis discussed how experience, based upon scientific information, can improve understanding, reduce uncertainty and minimize concern over products. This experience also forms the basis for approaching new product situations. The ISBGMO symposia provide a valuable mechanism to capture the advancements of our understanding of any effects transgenic organisms are having on the environment. As the pace of application of the technology increases for development of new products, regulatory frameworks will continue to evolve. To assure effectiveness and feasibility of regulation and risk assessment, data and information requirements need to be appropriate to the case and the risk presented. Transparency of the risk assessment process, including clarification and communication of methodologies used, can inform and reassure the public.

\section{Disclaimer}

Sally L. McCammon is the Science Advisor at BRS, APHIS, USDA. The views expressed in this paper are those of the author and do not necessarily represent those of the United States Government.

\section{Session 2: Introgression, invasion and fitness}

\author{
Bao-Rong LU ${ }^{1}$ and Rosie HAILS ${ }^{2}$ \\ ${ }^{1}$ Ministry of Education Key Laboratory for Biodiversity Sci- \\ ence and Ecological Engineering, Institute of Biodiversity \\ Science, School of Life Sciences, Fudan University, P.R. \\ China \\ ${ }^{2}$ Centre for Ecology and Hydrology, Mansfield Road, Oxford, \\ OX1 3SR, UK
}

\section{Presentations:}

1. The fitness of hybrids and progenies between weedy rice and $\mathrm{Bt}$ rice. Bao-Rong $\mathrm{Lu}$ (China)

2. From hybridisation to introgression models: Predicting the fate of a transgene in wild relatives based on linkage disequilibrium relations. Danny Hooftman (The Netherlands)

3. Ecology and evolution of crop-wild hybrids: a baseline for GM risk assessment. Allison A. Snow (USA)

4. The potential for management to contain invasive genotypes: lessons from invasive plants. Yvonne Buckley (Australia)

5. Measuring and modelling the fate of GM hybrids in the real world. James Bullock (UK)

6. Tools for regulators to predict relative invasiveness in plants. Rosie Hails (UK)

\section{Introduction}

Escape of transgenes from genetically modified (GM) crops to their wild relatives through pollen-mediated gene flow, and the undesired environmental consequences from such transgene escape are still a great biosafety concern worldwide. Risk assessment 
of potential environmental consequences caused by transgene escape from GM crops involves examination of a number of steps from pollen-mediated gene flow through to fitness changes, following the introgression of transgenes into wild relatives of crops. Pollen-mediated gene flow from crops to their wild relatives has been extensively studied during the past decade. Based on these studies, it is well recognized that many cultivated plants are able to hybridize with their sexually compatible wild relatives, including their conspecific weeds, potentially enabling introgression of transgenes into wild and weed populations.

The successful introgression and naturalization of transgenes will be largely determined by reproductive factors and by any advantages to the wild individuals and populations associated with the transgene. If a transgene encodes traits that are advantageous under natural selection in particular environments, it may enhance the transgene introgression into wild or weedy populations. This may consequently increase the invasiveness of the wild or weedy populations picking up the transgene, which may cause environmental damage. It is therefore essential to determine the introgression and naturalization of (trans)genes, and their impacts on plant phenology, following hybridization in wild and weedy populations for the effective assessment of environmental consequences associated with transgene flow. The goal of this session was to examine methodologies for determining the likelihood of naturalization and invasiveness of plant populations, and options for control of invasive plants, based on examples from both GM plants and introduced species.

\section{Determining fitness of transgenes after hybridization}

Introgression and naturalization of transgenes in wild or weedy plant populations depend greatly on the fitness associated with the transgenic traits and whether they increase natural selection advantage. Experiments or modeling methods are required in order to determine fitness of a transgenic crop-wild hybrid and to assess environmental impacts.

Using weedy rice (Oryza sativa f. spontanea) as a case, Bao-Rong Lu reported the recent studies on fitness changes in crop-weedy hybrids having insect resistance transgenes under experimental conditions. Weedy rice becomes one of the most noxious weeds in regions where direct seeding or no-till cultivation is replacing rice transplanting practices. Rapid adaptive evolution of weedy rice is likely to be associated with hybridization and introgression of weedy rice with the concomitant rice cultivars as elite crop genes can be continuously incorporated into weedy rice populations by recurrent hybridization and introgression. The occurrence of transgene flow from GM rice to weedy rice through hybridization and introgression may complicate the situation, causing potential environmental consequences. Introducing novel transgenes resistant to biotic and abiotic stresses from GM rice may enhance the fitness and change evolution process of weedy rice. This may alter population dynamics of weedy rice and increase the difficulties for controlling weedy populations that have acquired transgenes.

To better understand the fitness change of weedy rice brought by transgenes, Bao-Rong $\mathrm{Lu}$ and his colleagues made comparative studies of $F_{1}$ hybrids and $F_{2}$ progenies from crosses between insect-resistant GM rice lines (Bt cryIAc and $C p T I$ ) and weedy rice strains from different sources, under experiment conditions. Field comparison of the $\mathrm{F}_{1}$ hybrids, $\mathrm{F}_{2}$ progeny, and weedy rice parents with different cultivation styles showed variable performances for different traits. $F_{1}$ hybrids showed higher numbers of spikelets and produced seeds with a greater 1000-grain weight than their weedy parents although with a lower number of filled seeds, which may increase possibility of transgene introgression into weedy rice populations. However, experiments involving $\mathrm{F}_{2}$ progenies with or without the transgenes under normal or low insect pressure showed only slightly better performance of individuals with transgenes than those without the transgenes, under normal insect pressure. Results from studies of $\mathrm{F}_{2}$ progeny demonstrated that transgenes can be introgressed into and persist in the weedy rice populations. The experimental studies illustrate the difficulties for estimating fitness under different experimental environment conditions. Further fitness studies involving larger sample sizes and more generations are required to have a more accurate estimation.

Danny Hooftman presented another method to estimate fitness of hybrids involving model simulation. Hypothetically, the spread of transgenes depends on the possibility of gene exchange between crop and wild taxa and the specific effects of a transgene on hybrid fitness. The outcome of the gene exchange will depend on the performance of crop-wild hybrids under natural selection that will weed out maladapted genotypes, leading to the establishment of successful phenotypes with elevated fitness. Therefore, the effects of transgenes could be estimated. The baseline is the dynamics of the crop-wild hybridization process and the putative effects of transgenes introduced in such a system are superimposed upon this baseline. Introgression of genes from crops will likely be at the level of chromosomal segments rather than at the gene level. Within such segments a gene could be beneficial to the recipient plant, leading to higher likelihood of survival. Surrounding neutral genes will tend to "hitchhike" along and increase in frequency through linkage disequilibrium (LD) with the beneficial gene. 
Conversely, neutral or even mildly disadvantageous genes could be blocked from introgression by being linked to a negatively selected gene.

A two-locus selection method for outcrossing species was presented by Danny Hooftman, to study the potential of hitchhiking, the persistence of LD, expected introgressed block size, and the rate of increase of selected and neutral crop genes into a wild gene pool. A hybridization complex was simulated for Lettuce (Lactuca sativa) and its wild relative Lactuca serriola with about $1 \%$ outcrossing rate. This approach combines recombination rates (based on genetic maps) and putative fitness effects of individual alleles. The two-locus model showed LD between crop and wild genes for tens of generations, even in largely outcrossing populations. Hitchhiking was strongly dependant on the anticipated recombination frequency among two loci interacting with (i) the relative fitness differences of the containing (transgenic) alleles at different loci and (ii) population size. In general, selection only partially sorts among offspring when alleles are added to the crops that differ in relative fitness from the wild relative. Replacement of alleles with lower fitness, by alleles with a higher relative fitness, is continuously counteracted by hitchhiking. Consequently, the general level of introgression of "neutral" genes could be higher than previously expected.

This method provided a more accurate estimate of the introgression likelihood for specific genes. Risk assessment using this method could increase the predictability of possible introgression or blocking of linked genes. A judicious choice of transgene insertion sites may further inhibit transgene escape because of their negative selection in a wild background genome in combination with one or more other biosafety constructs.

\section{Evolutionary changes in crop-wild hybrids}

Introgression of new (trans)genes from crops may affect the fitness of recipient wild populations. Therefore, the measurement of fitness is an important procedure directly relevant to questions about how easily transgenic traits can persist in wild populations, and how these traits could affect weediness or invasiveness. Given the complexity of fitness measurements in crop-wild hybrids, it may be necessary to monitor the long-term effects of introgression of crop genes into wild populations. Using case studies of Raphanus raphanistrum and their crop-wild hybrids ( $R$. raphanistrum $\times R$. sativus), Alison Snow and her colleagues presented results of their longterm studies from experimental populations in Michigan, USA. They found that crop alleles persisted in experimental populations for more than ten years, despite an initial reduction in the fitness of F1 hybrids. Common garden experiments in Michigan and California showed that advanced-generation hybrids evolved greater pollen fertility than F1 plants and had greater survival and fecundity than their wild parents in a novel environment (in California). Thus, field studies of evolving crop-wild hybrids showed that conventional crop alleles can increase the fitness of their wild relatives in some cases. Added effects of fitness-enhancing transgenes could further improve the fecundity of hybrid populations, as observed in Bt sunflower. Based on these findings, Alison Snow emphasized three main points:

- Relative differences in fitness often change across environments, so it is important to study fitness in more than one season or location, as well as under different local conditions.

- The fitness of early-generation crop-wild hybrids can improve in more advanced generations.

- Investigators often focus on seedling survival, fecundity, or biomass as indicators of relative fitness, but some studies have shown that these fitness components can lead to inaccurate predictions. Ideally, all life history stages should be studied so results can be used in population growth models.

\section{Long-term monitoring of crop genes in natural habitats}

Fitness can be measured at a population level using data on the rate of population increase that can be determined directly or projected using matrix models. James Bullock described experimental and modeling studies of fitness changes involving Brassica rapa $\times$ B. napus hybrids sown into natural habitats and field crops. The complete life-cycle was measured in each experimental manipulation. Such long-term studies on Brassica can facilitate the determination of the utility of this modelling approach in GM risk assessment. Results from hybrid performance indicated that hybrids generally could not survive in natural habitats, or the survived hybrids showed lower fitness than their wild parents. On the other hand, hybrids differed only in fecundity and were able to persist in the crop habitats, albeit with a much lower population growth rate than either parent. In general, an ability to persist in the seed-bank was a critical determinant of population growth rate in the wild habitats, while fecundity was the main determinant of fitness in the crop habitats.

Studies on wild and crop species in multiple habitats over several years showed that demographic parameters and population growth rate was highly variable in time and space, suggesting stochastic formulations of matrix models to be more informative than deterministic approaches. Further modeling analysis of the impact 
of stochastic processes on long-term population growth indicated that increased disturbance frequency aided population growth. Based on long-term studies of Brassica hybrids, James Bullock concluded that the matrix modeling approach allows moving beyond conjecture and making hard predictions about the risks from GM plants. Matrix modeling can also quantify important processes of stochasticity and density dependence in crop and wild habitats, and thus should be more widely implemented in risk assessment research.

\section{The potential for management to contain invasive genotypes}

The study of invasive plants is analogous to the issue of the introduction of new genotypes (genes) of plants. Yvonne Buckley presented a recently developed model for risk assessment and management of invasive genotypes used for assessing potentially invasive plant species.

A central principle of invasive species management is that "a stitch in time saves nine", meaning that managing an invasion in its early stages will be more cost-effective than managing larger populations and areas. However, early interventions are fraught with uncertainty, and we have little information on how robust management strategies are likely to be in the face of uncertainty. A start has been made on general rules for local management of species when we have little information at the start of an invasion. An understanding of dispersal vectors can enable landscape-scale management to be optimized. Given the importance of landscape structure and dispersal for invader spread, more work is needed on guidelines which can be applied at the landscape scale.

There is an increasing realization that the potential commercial benefits of introduced plants should be weighed against the risks of invasion and the costs of subsequent containment. Whether to manage, and how much to invest in management, can be determined from the density-impact curves. Clear determination of impacts and how they scale with invader density are therefore essential before management decisions can be made.

The deliberate importation of commercial plants is one of the most frequent pathways by which invasive plants have been introduced. If future "commercial weeds" are assessed in an appropriate cost-benefit framework, a consideration will whether the costs of management should be assigned to those who will benefit.

\section{Tools for regulators to predict relative invasiveness in plants}

Based on the recent workshop held at Landcare Research, Christchurch, NZ, Rosie Hails summarized the outcome of the workshop. In the early days of risk assessment of GM plants, comparisons were drawn between successful weeds, non-native invasive plants and the GM plant being reviewed. However, this approach to risk assessment was quickly replaced with the current approach, in which the GM plant is compared to its non-GM counterpart, as the ability to define what makes a successful weed is very poor. This current approach has been fit for purpose to date, but there are regulatory challenges on the horizon which suggest re-evaluating assessments of invasiveness. Weed risk assessment has also developed considerably over the last two decades, and current risk assessment approaches are no longer considered by some to be using the best science available.

The two-day workshop reviewed current processes employed by regulatory agencies for non-native and GM plants, with a discussion of strengths and weaknesses. It was concluded that the current process would probably detect a GM plant with a potential to become invasive, but could also reject non-invasive plants broadly beneficial to agriculture and the environment. Weed scientists then presented current research into predictors of invasiveness. Large databases, multi-species studies and statistical techniques have illustrated that invasive plants are frequently characterized by combinations of traits, and that we now have a much better idea as to what those combinations are. Thus the workshop participants reached an easy consensus that the assessment of potential invasiveness for GM plants and non-native plants should be developed under a common conceptual framework.

A number of potential frameworks were then explored, including the Weed Risk Assessment System, a Critical Pathway Approach and Bayesian Belief Networks. It was concluded that each of these had different merits, but that no one existing tool is entirely appropriate. The aim is to take this forward in future workshops and to discuss at future ISBGMOs.

\section{Session 3: Biotic and abiotic stress resistance}

\section{Ervin BALÁZs}

Department of Applied Genomics, Agricultural Research Institute, 2462 Martonvásár, Brunszvik u. 2, Hungary

\section{Presentations:}

1. Evolution of the risks that recombination in transgenic plants expressing a viral coat protein gene would lead to the emergence of novel viruses. Mark Tepfer (Italy)

2. Risk assessment of virus-resistant pasture plants: a case study using the model Trifolium repens - 
clover yellow vein virus pathosystem. Robert Godfree (Australia)

3. Honeysweet: A hope for stone fruit growers. Michel Ravelonandro (France)

4. Development of field evaluation of transgenic crops and pastures for enhanced quality, biotic and abiotic stress tolerance traits. German Spangenberg (Australia)

5. Planning environmental risk assessment for genetically modified crops: Problem formulation for stress tolerant crops. Thomas Nickson (USA)

6. Assessing the impact of $\mathrm{Bt}$ maize pollen on lacewings. Jörg Romeis (Switzerland)

7. Studies of gene dispersal from soy bean to wild soy in their cultural habitat in Japan. Akito Kaga (Japan)

\section{Introduction}

Transgenic crops are considered a potential risk if they contain a trait that confers a significant fitness advantage in a natural situation. Since the beginning of the plant transgenic era this phenomenon has been carefully considered by the scientists who developed this technology. More than a decade ago, when commercial production was started, we had only limited experience and knowledge on the potential ecological impacts of transgenic plants on a large scale. During the same-period several biosafety experiments were performed, including risk modeling, mitigation processes and risk management. In the 2000 millennium year, the UN Secretary General called for a "Blue Revolution" in agriculture as the world population is growing rapidly, desertification is increasing and we need to wring more crops out of dry land as we are faced with water scarcity. This also reflects the phenomenon of global climate change, which is manifested in meteorological extremes. Floods, droughts and weather extremes frequently cause huge losses in agriculture. The first generations of transgenic crops of maize, canola, cotton and soybean that were widely commercialized were engineered to be tolerant to herbicides and/or insects. Although these crops were planted on over 114 million hectares in 2007 all over the World (www.isaaa.com) no unanticipated negative impacts on the environment or on animal and human health has been reported. In addition hundreds of plant-transgene combinations are being tested under experimental field conditions. These are ready for large-scale introduction, and include several which respond well to abiotic stress challenges. In the series of biennial ISBGMO initiated twenty years ago, the biosafety aspects of biotic stress tolerant plants have always been included in the conference programme. This time, in Wellington the scientific organizing committee of the 10th ISBGMO devoted a whole session to this subject.

\section{Potential ecological impact of transgenic virus resistant plants}

The first transgenic virus-resistant plants were described in 1986 by Abel and his co-workers (Abel et al., 1986), who showed that tobacco and tomato plants expressing tobacco mosaic virus coat protein gene were resistant to challenge infections. Since then, their results have been confirmed in more than a hundred different host/virus combinations, and in several cases plants have been field tested and even released for commercial use. One of the great successes of this approach was the release of papaya hybrids resistant to papaya ring spot virus. Transgenic virus-resistant hybrid papaya plantations have proved their economic feasibility. Since transgenic papaya was released in Hawaii, farmers have been able to cultivate non-transgenic papaya too, due to the low level of virus infestation caused by the presence of the transgenic crop (Gonsalves, 2003). When the first transgenic virus-tolerant crops were introduced, the potential risks associated with these plants were described and analyzed. A series of virus recombination studies was initiated in both transgenic and non transgenic plants to determine the baseline of virus recombination (see Tepfer and Balázs, 1997). In this session Mark Tepfer summarized the research of his team in the context of the achievements of others and showed that during the last two decades no new risks have been found for transgenic virus-resistant plants (Tepfer, 2002). The extensive research done in this field has made the technology safer, by eliminating transgene sequences which may contain recombination hot spots, or by preventing the synthesis of certain protein products. By elucidating the mechanism of transgenic coat-protein mediated resistance it has become obvious that a silencing mechanism controls this type of resistance. His extensive series of experiments, along with the other research results presented, proved that there is no more risk of recombinant viruses emerging in cucumovirus-resistant transgenic plants than there is in non-transgenic plants.

Michel Ravelonandro, the co-inventor of the Honeysweet plum pox-resistant plum, which involves the same coat protein-mediated approach, presented the results of field experiments carried out in three different agro-ecological regions. In field test plantations in Poland, Romania and Spain no recombinant plum pox virus strain emerged from these plants.

The results presented in these two talks on perennial dicotyledonous plants and transgenic virus-resistant woody plants were supported by a poster on recombination 
studies in monocot plants, involving studies on maize dwarf mosaic potyvirus in non-transgenic maize plants (Balázs et al., 2008).

Robert Godfree presented surveys on montane and sub-alpine Trifolium repens populations in southeast Australia, indicating that clover yellow vein virus is present in more than $80 \%$ of the plant populations. Greenhouse experiments suggested that the expansion of non-target host plant populations following the introduction of compatible disease-resistant genotypes into the environment is a plausible scenario, but that the level of ecological release is likely to be dependent on the spatial distribution and abundance of both pathogen and host, and on the co-evolutionary history of the pathosystem. He underlined the importance of incorporating a complementary set of field surveys, plant community analyses, tiered glasshouse/field experiments and the in situ monitoring of wild populations into protocols for assessing the biosafety of released disease-resistant plants in general. His talk was partly based on an earlier publication (Godfree et al., 2007).

German Spangenberg summarized a series of small field trials on new transgenic crops with improved quality and biotic and abiotic stress resistance, suggesting that these plants are ready for detailed studies on biosafety aspects before large-scale release.

\section{Planning environmental risk assessment for GM stress tolerant plants}

Risk assessment formulation is a new scientific discipline and has become general practice in the decision making process when a new technology is considered for use in today's agriculture. The companies, involved in the development of transgenic plants have set up biosafety units with a strong commitment to study all safety aspects before their products are released. As the first results are available from the use of functional genomics, their use in identifying abiotic and biotic stress-resistant genes and in transforming crop plants to obtain tolerant crops is being developed. Plants are very close to the field testing stage and so, to meet the regulatory requirements for the introduction of new plants into practice, environmental risk assessment and management must be carried out. An overview of problem formulation for a hypothetical drought-tolerant maize was presented by Thomas Nickson. This started with endpoint assessment, followed by a conceptual model, and finished with an analysis plan. His talk, previously published in detail (Nickson, 2008) integrated knowledge in a systematic and wellorganized manner to help risk assessors to develop conceptual models and analysis plans. His presentation and an earlier paper by Raybould (2007), who compared ecological and ecotoxicological methods for assessing the environmental risks of transgenic crops, are extremely valuable studies for decision makers.

\section{Assessing the impact of bt maize pollen on adult green lacewings}

Jorg Romeis, who has published several scientific papers on the effect of Bt maize pollen on non-target insects presented a detailed impact analysis of this issue. His results clearly showed that adults of common green lacewing are not affected by Bt maize pollen and are not sensitive to $\mathrm{Cry} 1 \mathrm{Ab}$ and $\mathrm{Cry} 3 \mathrm{Bb} 1$ at concentrations exceeding the levels in expressed pollen. Thus Bt maize pollen consumption poses a negligible risk to the adult of these species. These studies are an important complement to the results on the sensitivity of lacewing larvae to the presence of Cry toxins in their prey and could be applied to the risk assessment of other crops and other maize hybrids expressing the same Cry proteins.

\section{Gene dispersal from soybean to wild soybean growing in their natural habitat}

As soybeans are one of the most commonly grown transgenic plants, their cultivation in a region where wild relatives are common or in their country of origin raises the questions of whether gene flow will occur to wild relatives and the consequences of transgene flow. Akito Kaga presented data on gene dispersal in different regions of Japan where wild soybean can be found near cultivated soybean plots. He found natural hybrids between wild and cultivated soybean. Seeds of these hybrids were allowed to grow and were monitored to determine whether the progenies would survive in the natural environment. Only one plant was found later in one prefecture and secondary gene dispersal from the intermediate plants was not observed. Introgressed plants were very rare in natural habitats, and the hybrids and their offspring showed low or no persistence.

\section{Session 4: GM animals}

\section{Götz LAIBLE}

AgResearch, Ruakura Research Centre, Hamilton, New Zealand

\section{Presentations:}

1. Development of disease-resistant animals. John Lowenthal (Australia) 
2. The approval of ATryn, the first commercial recombinant form of human antithrombin. Harry Meade (USA)

3. Emerging international regulatory policy and risk assessment for genetically modified insects. Camilla Beech (UK)

4. Uncertainties associated with environmental risk assessment data from laboratory facilities: A transgenic coho salmon model. Robert Devlin (Canada)

5. Mating behaviour may affect the invasion success of growth enhanced fish. Kata-Riina Valosaari (Finland)

\section{Introduction}

Transgenic technology allows the modification of the genomes of a diverse range of animal species spread over several classes of animals, including insects, fish, birds and mammals. With the diversity in animal species comes a similarly broad range of applications in the biomedical and agricultural field. Depending on the specific application, transgenic animals can be intended for strict containment or full environmental release. The objective of the session was to showcase an assorted selection of some of the most advanced applications in different animal species and identify and discuss the particular risks associated with the different transgenic animal applications.

\section{Large domestic animals for the production of biopharmaceutical proteins in milk}

Over centuries we have gained extensive experience in the farming and containment of large domestic animals. It is generally accepted that it is relatively simple to control breeding and keep domestic animals safely in physical containment which is exemplified by the routine practise of containing cattle behind a single electrified wire. It is therefore highly unlikely that the farming of domesticated transgenic animals will cause any more environmental impact than the farming of conventional animals. Rather, some of the transgenic applications may even be aimed at reducing the impact on the environment and could be targeted towards the reduction of animal-related over fertilization of soils and waterways, green house gas emissions and land use.

Environmental risk considerations are probably at their most intense for transgenic dairy animals engineered for the production of a recombinant protein in milk for human medical applications, as was illustrated by the presentation of Harry Meade. In this case the benchmark is set far beyond efforts to keep the animals in containment but rather ensuring minimisation of any impact the environment might have on the animals by strictly controlling everything that is introduced into the containment. The mandatory controls associated with the production and commercialization of the first recombinant protein produced in an animal are aimed at minimising the exposure of animals and contamination of their products with pathogenic agents, to ensure product safety. Conversely, the strictly controlled farming of these animals will minimise any adverse environmental risks.

\section{Development of disease resistant animals}

Another prominent application of transgenic animal technology is the modification of the genome to make animals more resistant to certain diseases. This objective can have a range of immediate benefits including improved animal welfare and production, increased food safety (if the animal is used in food production) and decreased risk of a potential spread of the disease to other animal species or humans. The relative emphasis for the different beneficial aspects will depend mainly on the targeted disease. The application illustrated in John Lowenthal's presentation addressed the very recent threat for human health from avian influenza that can be transmitted by diseased poultry. The introduction of an expression construct for an interfering RNA (RNAi) which can disrupt the virus's lifecycle will essentially boost the natural RNAi defence, which is often overwhelmed by the virus. The project is still in the beginning of the research and development phase. Assuming that resistance against avian influenza can be achieved with this approach, the next issue will be the safety of foods produced by these animals. Although the introduced disease resistance trait relies on an existing endogenous defence mechanism, food safety requirements need to be fully satisfied before these chickens can be commercialized. While there will be clear environmental benefits, any potential adverse effects for the environment could be minimized with the implementation of controlled farming operations.

\section{Genetically modified insects for disease control}

Insects are being genetically modified for various biomedical and agricultural applications. While the production of recombinant animal proteins is an activity intended to occur in containment, the control of disease vectors and plant and animal pests with genetically modified insects requires their release in the environment. Current projects 
are aimed at using genetic modification to improve the 'conventional' Sterile Insect Technique (SIT) which is successfully used for area-wide control programmes for vector and pest populations. SIT involves large scale release of radiation-sterilized males to suppress target insect populations through infertile matings. The introduction of a repressible female-lethal system via transgenic technology, described by Camilla Beech, combines genetic sexing and genetic sterilization, which circumvents the requirement for irradiation and can be more readily applied to a broad range of insect species than conventional SIT. The transgenic system allows the mass rearing of insects under repressive conditions and the isolation of male-only populations for release by simply removing the repressor which triggers the expression of the lethal gene in all females. The expression of the lethal gene and killing of all female carriers as the default state in any release or escape event provides a fail-safe biocontainment with the gene construct rapidly disappearing from the population if not constantly replenished with engineered insects. While the large scale release of irradiated, highly mutagenized insects is an accepted practise, improved strategies using engineered insects with well defined and sophisticated genetic elements for the contained and reversible control of insect vectors and pests, are perceived to carry a greater residual risk, despite very successful open field release trials that revealed no significant environmental impact. It highlights the need to incorporate strong science based evidence in the developing regulatory frameworks. In addition, the application of the technology to control the insect vectors for serious human diseases such as dengue fever which was outlined in the presentation, provides strong support for the view that any potential risks should be assessed in relation to the potential benefits. Unfortunately, the legislative regulations of some countries are solely focused on risks and do not consider benefits at all.

\section{Growth enhanced fish}

The major applications for transgenic fish are centred on increased production and disease resistance. The growth enhancement of fish engineered for the expression of additional growth hormone has been particularly successful, resulting in transgenic fish reaching double the normal body size in half the normal time of growth. Although the use of these fish is intended for containment, the large scale of their aquaculture combined with a vast natural habitat pose significant containment issues and raise concerns on their environmental impacts should they escape. Some growth-enhanced fish show a number of pleiotropic effects, including behavioural differences which might increase their fitness, with implications for the entire ecosystem. These issues were addressed in two presentations by Robert Devlin and Kata-Riina Valosaari. They concluded that the assessment of the environmental impact of growth enhanced fish is highly complex, and despite great efforts to evaluate different aspects in laboratory experiments and mathematical modelling, this approach cannot fully recapitulate the natural situation and thus carries substantial uncertainties. Even with improved methods and additional containment and biocontainment measures such as land-based facilities and sterilization methods, aspects of residual risk will remain. Until the benefits of the increased and possibly more sustainable production of transgenic fish by aquaculture are perceived to outweigh its risk, commercialization of these transgenic fish appears unlikely.

\section{Session 5. Effects of GM crops on soil ecosystems}

\section{Kornelia SMALLA ${ }^{1}$, Maureen O'CALLAGHAN ${ }^{2}$, Jim GERMIDA ${ }^{3}$, Sandrine DEMANÈCHE ${ }^{4}$, Christoph C. TEBBE ${ }^{5}$, Leda MENDONÇA-HAGLER ${ }^{6}$}

${ }^{1}$ Julius Kühn-Institut (JKI), Institute for Epidemiology and Pathogen Diagnostics, Messeweg 11-12, 38104 Braunschweig, Germany

2 AgResearch, Lincoln Research Centre, Private Bag 4749, Christchurch 8140, New Zealand

${ }^{3}$ Department of Soil Science, College of Agriculture and Bioresources, University of Saskatchewan, Saskatoon SK S7N 5A8, Canada

${ }^{4}$ Environmental Microbial Genomics Group, Laboratoire AMPERE, UMR CNRS 5005, École Centrale de Lyon, Université de Lyon, 36 avenue Guy de Collongue, 69134 Ecully, France

5 Johann Heinrich von Thünen-Institut (vTI), Institute for Biodiversity, Bundesallee 50, 38116 Braunschweig, Germany

${ }^{6}$ Universidade Federal do Rio de Janeiro, Instituto de Microbiologia, Cidade Universitaria - CCS Bloco I, 21949-590 Rio de Janeiro, Brazil

\section{Presentations:}

1. Influence of transgenic crop release on the functioning of soil. Konny Smalla (Germany)

2. Effect of GM plants on non-target soil biota. Maureen O'Callaghan (New Zealand)

3. Biotic and abiotic regulation of recombinant DNA transfer from transgenic plants to soil bacteria. Sandrine Demanèche (France)

4. Fate and microbiological interactions of Bt-toxins (Cry-proteins) in soil. Christoph C. Tebbe, Petra 
Möbus, Rona-Miethling-Graff, Susanne Baumgarte and Rainer Martens (Germany)

5. Influence of field site on the diversity of soil bacterial communities associated with 4 varieties of GM canola. Jim Germida (Canada)

6. Studies on the degradation of Cry1Ac protein by rhizospheric bacteria in Bt cotton soil. Deise Capalbo (Brazil)

7. Direct extraction of soil DNA for denaturing gradient gel electrophoresis (DGGE), to study the influence of different transgenic papaya lines on soil bacterial communities. Ce-Shing Sheu, Chung-Yi Wu, Shu-Chuan Chen and Chi-Chu Lo (Taiwan)

Session 5 of the 10th ISBGMO was dedicated to studies addressing potential effects of genetically modified (GM) plants on soil biota. The session was chaired by Leda Mendonça-Hagler (Brazil) and Kornelia Smalla (Germany). Themes discussed in the session were (1) the effects on soil microbial communities and the soil mesofauna, (2) horizontal gene transfer (HGT) and (3) the fate of Bt-toxin.

Background for this session was that the overall impacts of GM crops on soil biota are still poorly understood. Despite their importance for soil functioning and plant health, studies on the response of soil organisms to GM plants are inherently difficult, simply due to the lack of appropriate methods. It is assumed that changes of soil microbial community composition might occur directly due to the biological activity of the transgene products or indirectly due to altered composition of root exudates, plant litter or changes in agricultural practice (Kowalchuk et al., 2003). In view of the importance of soil microorganisms for soil functions, geochemical cycles, and plant health, different contributions to this session stressed that it is important to understand and predict potential effects of GM plants on the soil biota.

\section{Effects on soil microbial communities and the soil mesofauna}

The most likely habitat that might be affected by transgene expression or altered root exudation is the rhizosphere. The rhizosphere is defined as the volume of soil adjacent to, and influenced by the plant root (Sørensen, 1997). In the proximity of plant roots not only an enhanced abundance but also metabolic activity of microbes that can utilize root exudates or deposits is observed (Brimecombe et al., 2001; Broeckling et al., 2008). The composition and amount of root exudates differs between different plant species (Bais et al., 2006; Neumann and Römheld, 2001). Rhizosphere microorganisms exert strong effects on plant growth and health by nutrient solubilization, $\mathrm{N}_{2}$ fixation, or production of plant hormones (Raaijmakers et al., 2008). Soil-borne pathogens can greatly reduce plant growth. Bacterial and fungal communities can be influenced by the plant as well as vice versa. In view of the importance of plant-microbe interactions in the rhizosphere (Singh et al., 2004) all speakers of the session emphasized that it is crucial to understand the factors that influence the microbial communities in the rhizosphere. To evaluate potential changes of microbial communities in the rhizosphere of GM crops compared to the parental line, it is of utmost importance that baseline data are provided to relate potential changes to natural fluctuations. A relevant effect of GM crops should cause deeper changes in the microbial community than the commonly accepted changes due to factors such as plant growth stages, different cultivars, soil type, or climate.

Kornelia Smalla presented the results of a project on the effect of potato plants with increased zeaxanthin content in their tubers as a result of antisense co-suppression. Effects of GM zeaxanthin-accumulating potato plants on microbial communities in the rhizosphere were compared to natural variability among different potato cultivars. Two GM lines, their parental cultivar as well as four other potato cultivars were grown in randomized field plots at two sites and in different years. Rhizosphere samples were taken at three stages of plant growth and analyzed by means of molecular fingerprints of Bacteria, Actinobacteria, Alpha- and Betaproteobacteria, Bacillus, Streptomycetaceae, Pseudomonas, gacA, Fungi and Ascomycetes. Significant differences between the parental and the two GM lines were mainly detected for Actinobacteria, but also for Betaproteobacteria and Streptomycetaceae, yet they occurred only at one site and in one year. For Fungi, especially for Ascomycetes, significant differences occurred more frequently than for bacteria. Comparing all seven plant genotypes, the fingerprint analysis revealed that different cultivars had a stronger effect on both bacterial and fungal communities than the genetic modification. Effects of the genetic modification were mostly detected at the senescence stage of the plants. The site was the overriding factor affecting microbial community structure compared to the plant genotype. In general, the fingerprints of the two GM lines were more similar to the parental cultivar, and observed differences did not exceed natural cultivar variability (Weinert et al., 2009a). The same trend was observed for the effects on cultivable bacteria with in vitro antagonistic activity (Weinert et al., 2009b) and for genes of the nitrogen cycle quantified by real time PCR.

Soil microorganisms work in combination with numerous soil-dwelling invertebrate species (e.g. earthworms, Collembola and nematodes) to carry out essential soil ecosystem processes such as nutrient cycling 
and decomposition. Issues and difficulties in the assessment of impacts of GM plants on non-target soil biota were discussed by Maureen O'Callaghan. It is impractical to collect biosafety data on the large numbers of potential non-target soil dwelling species in the receiving environment of each GM crop, so a key issue is the selection of appropriate test species for non-target testing of soil fauna. Often the species used in testing for non-target effects are chosen because they are easily reared in the laboratory, but these species may not provide useful information about potential environmental impacts. There are few reliable indicator species for important ecological processes carried out by soil micro- and meso-fauna, although Birch et al. (2007) selected a useful list of "indicator groups" of soil biota that could be assessed on laboratory, glasshouse and laboratory scales.

There are also significant technical challenges in the execution of non-target testing against soil fauna. It is important that test species are exposed to realistic amounts of transgene-derived proteins during testing, but with the exception of Bt protein there are no methods by which these proteins can be tracked in soil. When testing the effects of GM tobacco expressing protease-inhibitor on three earthworm species, it was necessary to regularly apply fresh GM plant material to pots to ensure that the earthworms were continually exposed to the protein throughout the experiment (O'Callaghan et al., 2007). Methods are needed to track the fate of other transgene-derived proteins in soil as potential non-target impacts in the field are dependent on protein persistence. It would be useful to know if each protein is mobile in soil or becomes bound to soil particles. Christeller et al. (2006) showed that the potent insecticidal protein avidin binds tightly to soils, and residual insecticidal activity varied with soil type and length of incubation in two New Zealand soils.

Another important issue for experimental design is the selection of appropriate controls. Often for practical reasons it is possible to study only a limited number of plant lines - most commonly the GM line and its near isogenic control. However, inclusion of unrelated cultivar controls can assist with discrimination between natural variation and effects of GM traits. During preliminary testing of GM plants, it is also important to assess several GM lines. For example, O'Callaghan et al. (2008) showed that geocaulosphere bacterial communities associated with two of three GM potato lines expressing magainin differed significantly from their unmodified parental line and an unrelated control cultivar, while the communities associated with the third GM line were more similar to those of the two control lines.

Many of the challenges and issues involved in conducting robust non-target testing of GM plants against soil fauna are common to assessment of effects on soil microorganisms and are inherent in working within the soil ecosystem. The heterogeneity of the soil environment, the complexity of communities present in soil, and the aggregation and patterns of movement of soil fauna present a significant challenge to the design of ecologically meaningful test methods (O'Callaghan et al., 2005). However, as the body of literature on non-target effects of GM crops increases, and tools such as meta-analysis are applied to data from numerous sites and seasons (e.g. Marvier et al., 2007), greater confidence can be placed in conclusions drawn from biosafety assessments on GM plants on soil microflora and fauna.

Germida and Dunfield presented an overview of their work assessing the influence of GM herbicidetolerant (GMHT) cropping systems on the soil ecosystem. A three-year field study assessed the effects of four GMHT canola cultivars on soil and plantassociated bacterial communities in western Canada. These included a Roundup Ready ${ }^{\circledR}$ cultivar, tolerant to glyphosate that contained the 5-enolpyruvylshikamate3-phosphate synthase (EPSPS) and glyphosate oxidoreductase $(G O X)$ genes, and three Liberty-Link ${ }^{\circledR}$ cultivars, tolerant to glufosinate-ammonium that contained the phosphinothricin acetyltransferase (PAT) gene and a kanamycin resistance gene (NPTII). Analysis of rhizosphere bacterial communities associated with GMHT and non-GMHT canola cultivars during the field season demonstrated that changes in microbial communities associated with GMHT plants exist, but are minor compared to the normal changes in the community associated with the rhizosphere effect, sampling date and field site subject to seasonal variation (Dunfield and Germida, 2003). In Saskatchewan, the effect of transgenic plants on the microbial community was temporary, and dependent on the presence of the plants.

Follow-up studies explored the interactions of glyphosate, and glyphosate cropping systems on the soil ecosystem. Recombinant DNA (rDNA) released from GM Roundup Ready ${ }^{\circledR}$ (RR) soybeans and corn plants and litter was detected in soil for up to two years, but the average persistence of CP4 EPSPS after crop harvest was low, between 1 to 10 copies per gram soil fresh weight (Gulden et al., 2008; Levy-Booth et al., 2007, 2008). The persistence of the genes in the soil is primarily influenced by environment (year) and edaphic factors (field site). Additional field studies showed transient effects of GM glyphosate-tolerant cropping systems on soil bacteria, fungal, protozoan, and nematode biomass (Powell et al., 2009). This could have implications for trophic interactions and nutrient cycling in these systems; however, none of the observed changes were permanent or widespread.

The interaction between microbial communities, transgenic plants and field site, along with the seasonal 
variability in microbial communities documented in these studies emphasizes the complexity and need for a multifaceted approach to study the risks of GMHT plants to the diversity of the microbial community (Dunfield and Germida, 2004).

\section{Horizontal gene transfer}

Horizontal gene transfer (HGT) between transgenic plants and soil bacteria was the topic of the contribution by Sandrine Demanèche. The possible transfer of recombinant DNA from transgenic plants to soil bacteria is one of the issues that feeds the ongoing debate about the ecological safety of gene technology. Societal concerns regarding the impact of GM plants on bacteria are especially related to the potential dissemination of antibiotic resistance determinants in the environment that raise fundamental questions about gene transfer between species and kingdoms.

An overview was given by Sandrine Demanèche of investigations to understand how HGT from GM plants to bacteria works. Typically, these studies conducted in planta demonstrated HGT from plants to bacteria, with localization of transformation events achieved by using a recipient bacterium fitted with a green fluorescent protein. Furthermore, results were presented from a field study conducted to evaluate the potential impact of transgenic plants on antibiotic microbial resistance in soil (Demanèche et al., 2008).

A bioinformatic search was used to look for the presence of homologies that would favour homologous recombination between transplastomic DNA and bacteria. Finally, a metagenomic approach was developed to detect the natural prevalence of transgenic markers in soil bacteria. Their results demonstrated that indigenous bacteria possess naturally a wide diversity of antibiotic resistance genes and that soil is a reservoir of genetic determinants that could allow bacteria to adapt rapidly to present and future environmental conditions. Cumulative data are now sufficiently informative to conclude that the risk of horizontal gene transfer from transgenic plants to bacteria is negligible. Although the genes may be transferred at very low frequencies, these genes are already present in soil bacteria and are subjected to constant evolution. Finally, Sandrine Demanèche concluded that the transfer of transgenic plant DNA to bacteria probably occurs in the environment considering the experimental evidences obtained in vitro, but also in planta and in soil. However, it remains very difficult to detect HGT under field conditions, and transfer frequencies will depend on the transgene sequence. Furthermore, concerning the potential impact, it was stressed that it will also depend on the genes involved but that, whatever the transgene, it will be counterbalanced by the natural bacterial biodiversity.

\section{Fate of Bt-toxins}

The fate of Bt-toxins in soil and their interactions with the resident microbial communities was the main focus of the talk given by Christoph Tebbe. Bt-toxins are probably the most abundant recombinant proteins deliberately released into the environment by agricultural use of GM plants. Several studies have demonstrated that typically, the amounts of Bt-toxins during and after cultivation of maize plants expressing Bt-toxin in field soil are low or non-detectable (Baumgarte and Tebbe, 2005; Head et al., 2002; Zwahlen et al., 2003). Low concentrations or lack of detection have been explained as an indication of their environmental instability caused by microbial degradation, but it should be noted that detection thresholds and extraction procedures should be considered when interpreting results. This is because previous studies have demonstrated that the Bt-toxins may be adsorbed by the soil mineral or organic fraction increasing their stability and persistence (Icoz and Stotzky, 2008; Tapp and Stotzky, 1995, 1998). Christoph Tebbe presented results from studies conducted to characterize the amounts of Cry1Ab (MON810) and Cry3Bb1 (MON88017) Bt-toxins released from maize in context of their agricultural use on experimental fields in Germany. Based on an improved extraction and purification technique, the Bt-toxins were quantified with the ELISA technique from soil, rhizospheres and post-harvest plant residues. Cry1Ab of MON810 was also quantified on "real" agricultural fields on which this maize cultivar had been cultivated over two to four years. Concentrations of $\mathrm{Cry} 1 \mathrm{Ab}$ during and immediately after cultivation were mostly in the range of $1 \mathrm{ng}$ per $\mathrm{g}$ of soil (Baumgarte and Tebbe, 2005) while values of Cry3Bb1 were up to $80 \%$ lower (threshold of detection $0.01 \mathrm{ng} \cdot \mathrm{g}^{-1}$ ). Higher amounts, in the $\mu \mathrm{g}$ per $\mathrm{g}$ range, were found in plant residues but these were degraded with the successive decay of the plant material during the following vegetation period. In general, soil persistence of Cry3Bb1 was lower than for Cry1Ab but even for the latter, accumulation of the Cry proteins in soil was never detected in fields which were planted with MON810 over several years. Field concentrations of detectable Cry1 Ab correlated negatively with the water holding capacity, soil organic matter and clay content, while $\mathrm{pH}$ values in the range between 4.6 and 6.4 had no significant correlations. However, it was suspected that ELISA detections of soil suspension extracted from fields with high organic carbon or a high proportion of clay will underestimate the actual amount of Cry $1 \mathrm{Ab}$ present. In order to further elucidate the fate of Cry $1 \mathrm{Ab}$, especially to differentiate between adsorption and degradation in soil, ${ }^{14} \mathrm{C}$-labelled molecules were synthesized with the help of a recombinant Escherichia coli strain. Soil samples kept under laboratory conditions were amended with concentrations of approx. $10 \mu \mathrm{g}{ }^{14} \mathrm{C}$ 
labelled Cry1 Ab.g ${ }^{-1}$. This was above actual concentrations expected in the field, but clearly below concentrations reported in the literature to study adsorption of $\mathrm{Cry} 1 \mathrm{Ab}$. The fate of ${ }^{14} \mathrm{C}$ was differentiated by measurements of ${ }^{14} \mathrm{CO}_{2},{ }^{14} \mathrm{C}$ incorporated into microbial biomass, the amount extractable with water or phosphate buffered saline (PBST), and from the non-extractable fractions, respectively. Both, degradation and adsorption processes could be detected and quantified. Interestingly, radioactivity detected in the water or PBST extractable fraction was mainly caused by degradation products of the Cryprotein, as confirmed by Western blotting and ELISA.

The structural diversity of the bacterial community inhabiting the maize rhizospheres was established by genetic profiling of PCR-amplified partial 16S rRNA genes using the single strand conformation polymorphism (SSCP) technique. Primers targeting different phylogenetic groups were included in addition to general primers potentially amplifying $16 \mathrm{~S}$ rRNA genes from all bacteria. Independent of the targeted phylogenetic group, the SSCP-profiles of the Bt-cultivars were highly similar to other cultivars included in the analyses and differences between bacterial communities of genetically engineered and non engineered cultivars never exceeded those seen between non-engineered cultivars (Baumgarte and Tebbe, 2005). The lack of response of the rhizosphere bacteria to MON810 or MON88017 was not surprising as the amounts of Cry-proteins detected in maize rhizospheres from fields were always very low, thus being insufficient to act as a bacterial toxin or to be utilized as a carbon source for considerable bacterial growth. However, the results of the studies presented should be helpful to develop models which will allow a prediction of Cryprotein concentrations in soils in the context of the agricultural use of Bt-maize and possibly other Bt-modified plants. None of their data supported known hypotheses assuming a risk of such plants to microbiologicallymediated soil functions or non-target organisms due to Bt-toxin accumulation.

Although microbial ecology has enormously developed in the last two decades and new methods became available which allow the study of microbes in soil and in the rhizosphere independent of their ability to form colonies on solid nutrient, it is still difficult to predict and assess effects of GM crops on soil microbiota, as agricultural soils are highly dynamic and changes in microbial community structure and function are a characteristic of high quality soils. Changes in the microbial community composition in the rhizosphere of GM crops compared to the non-modified cultivar need to be related to natural variation due to biotic and abiotic factors such as soil type, plant species or cultivar. The studies presented in Session 5 indicate that factors such as site, year-to-year variation, changes during plant growth development have a stronger influence on the microbial community composition in the rhizosphere than the plant genotype. Still the presentations overwhelmingly stated that microbial ecologists are just starting to get a clearer picture of the factors that shape the structural and functional composition of soil microbial communities and to open the "black box" associated with soil studies. Owing to the great importance of the soil microbiota for soil health and nutrient matter cycling, future research needs to continue to unravel the complex below ground interplay of bacteria, archaea, fungi, soil-dwelling invertebrate species (e.g. earthworms, collembola and nematodes), and plants.

\section{Session 7: Biocontainment methods}

\section{Joachim SCHIEMANN}

Julius Kühn-Institut, Germany

\section{Presentations:}

1. An overview of biocontainment methods for GM plants. Ruud de Maagd (Netherlands)

2. Biosafety aspects of transplastomic plants. Ralph Bock (Germany)

3. New strategies (molecular approaches) to prevent gene escape. Stephen M. Swain (Australia)

4. Managing containment of GM field tests in NZ. Kieran Elborough (New Zealand)

5. No seed dormancy - no volunteers - no gene escape: A biological confinement strategy for GM oilseed rape (Brassica napus)? Sabine Gruber (Germany)

6. Cleistogamous oilseed rape: a way to contain pollen at the field scale? Alexandra Hüsken (Germany)

7. Superwoman1-cleistogamy, a hopeful mutant allele for gene containment in GM rice. Hitoshi Yoshida (Japan)

\section{Introduction}

Biological containment (or biocontainment) describes measures aimed at preventing genetically modified organisms (GMOs) and their transgenes from spreading into the environment. Biological containment can be seen as a tool to support economically driven co-existence measures or as a tool to improve the biosafety of genetically modified (GM) plants in cases where a risk for human health or the environment has been identified. By developing efficient, stable, environmentally safe and commercially viable biological containment strategies for GM plants, co-existence of GM and non-GM 
agriculture can be promoted and rules for co-existence might be improved and simplified. Since co-existence is not a safety issue, biological containment has not been discussed in this context during the symposium.

Biocontainment may also play an important role to reduce the environmental exposure of GM plants which might be necessary for particular applications. Where new potential GM plant risks are identified, the plants are likely to require more specific risk management conditions, such as defined confinement measures. This is exemplified for certain GM plants used for non-food or non-feed purposes. A recently published EFSA guidance (EFSA, 2009) stated that the risk assessment has to take into account any confinement measures to be applied to a commercialised GM plant. Applicants should describe the details and rationale for the proposed physical and biological confinement strategy, where applicable. The proposal should specify the methodology used and its effectiveness in reducing accidental intake or preventing gene flow into the environment.

\section{Session 7}

This session provided a broad overview of biocontainment including biosafety aspects, new scientific approaches, evaluation of biocontainment tools for specific crops, and management aspects. In the following, the main topics of the seven talks given in this session are described on the basis of the abstracts provided.

Ruud de Maagd described how the EU FP6 project TransContainer is investigating and developing a number of strategies for biological containment:

- Plastid transformation as a means to prevent transgene spread;

- Prevention of flowering as biological containment strategy;

- Controlling transgene transmission through pollen and seed.

Where necessary, the project aims to complement these strategies with tightly controllable switches to restore fertility. Besides developing biological containment strategies, the project is also:

- Investigating the impact of the implementation of these strategies on environmental and food safety and on the possible improvement of co-existence rules;

- Assessing the agro-economic effects for European agriculture and compares different scenarios for co-existence;

- Invoking stakeholder dialogues on socio-economic and environmental issues by holding interviews and workshops for stakeholders and the public;

- Communicating co-existence issues and results of the project to stakeholders and the general public.
To examine biosafety aspects of transplastomic plants, Ralph Bock and colleagues have designed an experimental system that facilitates stringent selection for occasional transmission of transgenic chloroplasts via pollen. Using this system and assaying more than two million progeny seedlings from crosses of wild-type plants to transplastomic plants, they have determined the frequency of occasional paternal plastid inheritance in a species (tobacco) that normally inherits its plastids maternally. They have also measured the frequency of paternal plastid transmission into the shoot apical meristem of F1 seedlings, which is the frequency relevant to transgene containment. They found this frequency to be very low (less than $3 \times 10^{-6}$ ) demonstrating that plastid transformation technology greatly increases transgene containment and thus significantly improves the biosafety of transgenic plants. However, complete prevention of transgene flow via pollen will require combination of plastid transformation with additional confinement strategies.

Steve Swain discussed the preliminary development of a genetic strategy to prevent transgene escape by blocking effective pollen flow from transgenic plants. He described a novel concept, based on epigenetic inheritance (imprinting) and post-transcriptional gene silencing (PTGS)/RNA interference (RNAi) using "hairpin" technology. A key advantage of this strategy is that it would allow all seeds from self-pollinated transgenic plants to be harvested and re-sown, without the need for specific treatments, while retaining all of the transgenes present in the parent. Thus, this strategy is not a Genetic Use Restriction Technology (GURT) and if implemented would not prevent seed saving by end users. This system could be employed either independently or as a backup for other strategies such as chloroplast transformation.

Kieran Elborough presented how containment of GM field tests in New Zealand is managed. In NZ the importation, development, field test, or release of GMOs is regulated under the Hazardous Substances and New Organisms Act 1996 (HSNO Act). Decisions on applications to introduce or develop GMOs are made by the Environmental Risk Management Authority (the Authority). The Authority is an independent, quasi-judicial decision making committee. The Authority is supported by an agency that processes the applications by reviewing and evaluating them, and carrying out assessments of risks, costs and benefits. Under the HSNO Act, research involving GMOs can be carried out as a contained field test undertaken outside of a containment structure. The HSNO Act defines a "field test" as "... the carrying on of trials on the effects of the organism under conditions similar to those of the environment into which the organism is likely to be released, but from which the organism, or any heritable material arising from it, could be retrieved or destroyed at the end of the trials". Field tests must comply 
with comprehensive structural and operational requirements (controls). The controls can be biological (such as prohibiting flowering to prevent dispersal of pollen) or physical (such as site and fencing requirements). The controls are determined by the Authority and the majority are imposed to prevent the release of the GMO into the open environment.

As an answer to the question: "No seed dormancy no volunteers - no gene escape: A biological confinement strategy for GM oilseed rape?" posed by Sabine Gruber, it was shown that there is a potential for low seed dormancy and low persistence capacity in the gene pool of oilseed rape. This could be used for breeding low-dormancy GM or conventional cultivars as a strategy to restrict dissemination. Also the question "Cleistogamous oilseed rape: A way to contain pollen at the field scale?" posed by Alexandra Husken, could be answered positively on the basis of European ring experiments testing the stability of the cleistogamous trait (self-fertilization without flower opening) in the field and estimating the rate of adventitious presence of allopollination in cleistogamous lines under several environmental conditions. The studies showed that cleistogamy as a biological mitigation technique has a major potential for limiting crosspollination due to the strong reduction of pollen emitted and received. Hitoshi Yoshida considered that for extending the cleistogamy concept to GM rice, the mutant allele Superwoman1 is a potential candidate for gene containment.

Several aspects presented in the talks were relevant to risk assessment/management:

(i) It is important to separate biosafety issues from coexistence issues, since the latter are economic considerations;

(ii) The probability of vertical and horizontal gene flow into wild relatives (e.g. oilseed rape), weedy relatives (e.g. rice, sugar beet), unrelated species and the same crop via pollen, seed, or DNA transfer is a significant part of the ERA;

(iii) Natural containment and restriction of gene flow is a feature of many species and organisms; for example with species crossing barriers and exceedingly low probability of gene flow from plants to bacteria;

(iv) There are no general solutions for biocontainment; biocontainment measures have to be implemented case-by-case, and their stability and reliability tested.

\section{Conclusions}

The main outcomes of Session 7 could be defined as follows:

- A broad spectrum of biocontainment tools are being developed, from pipeline to field evaluation;
- The adaptation of biocontainment tools for specific situations (crop/trait) is possible;

- Management problems (e.g. oilseed rape volunteers) have been identified, solutions will be offered by classical breeding and/or genetic engineering;

- Quantifying the reliability of biocontainment tools is possible, e.g. transplastomic tobacco, cleistogamous oilseed rape;

- Effective containment should be possible by integration or use of more than one containment tool;

- Biocontainment solutions for special non-food/feed applications should be possible.

To improve biocontainment, basic research is needed on model and crop plants, including biosafety evaluation of new tools. However, in doing so, are we creating other/new safety issues? E.g. transplastomics: horizontal gene transfer, GMO quantification. On the other hand, reliability and stability of already established biocontainment tools in different situations have to be tested, including field tests under different climatic conditions. Biocontainment tools have to be adapted for specific crop/trait combinations, and may include using combinations (stacking) of containment tools.

\section{Session 8. Post market environmental monitoring}

\section{Jeremy SWEET}

Cambridge, UK

\section{Presentations:}

1. Studies on the operational and environmental safety of genetically modified Pinus radiata in a field trial. Christian Walter (New Zealand)

2. Post release monitoring of Bt cotton in Australia. Gary Fitt (Australia)

3. Monitoring or surveillance? Balancing between theoretic frameworks and practical tools. Franz Bigler (Switzerland)

4. Data surveys, analysis and tools for post-market environmental monitoring - the European approach. Kerstin Schmidt (Germany)

5. Bt maize monitoring at a national level in the $\mathrm{EU}$; the German example. Detlef Bartsch (Germany)

\section{Introduction}

Post market monitoring can be a useful tool for examining uncertainties in ERA and for observing anticipated and unanticipated post market environmental impacts. 
It is important that the methods and systems used are designed to meet clear scientific objectives and to inform risk managers, regulators and provide feedback for risk assessors. This session examined monitoring programmes in different countries with different GM crops and objectives, and the lessons learnt from these programmes.

Christian Walter described a pre-marketing monitoring programme of the first experimental releases of GM pine containing an antibiotic resistance marker gene in New Zealand. This multidisciplinary monitoring was conducted by a large scientific team on the basis of no risk hypothesis but in order to study biota associated with the pine trees and to determine whether any unintended effects occurred. The monitoring was more of a research project than a risk assessment/risk management study and helped to develop experience and expertise in studying impacts on a range of soil and above ground biota. No adverse effects were anticipated by the risk assessment and no unintended or unanticipated effects were detected, hence confirming the original risk assessment.

\section{Case specific monitoring}

Gary Fitt reported on the post market management of cry-toxin resistance development in cotton boll worm in Australia. Various strategies were being used, including use of non-GM refugia, restrictions on the area of cultivation and cultivation of GM cotton cultivars expressing more than one cry toxin. Monitoring programmes were established which regularly sampled and tested bollworms from regions of GM cotton cultivation and from other regions. Monitoring of the pest had revealed no significant increase in resistance to cry toxins indicating that these strategies are effective in maintaining resistance at current levels even though GM cotton is now the majority cotton type cultivated. While no resistance has been detected in target pests in Australia, there appear to be some shifts in sensitivity of target pests in USA. The approach in Australia was considered to be scientifically sound and well justified. It provides a welcome reminder that a combination of good resistance management and careful monitoring is the most appropriate way to introduce and exploit insect-resistant crops. In addition this presentation emphasized the importance of effective monitoring as part of risk management strategies.

\section{Monitoring in the EU}

Franz Bigler discussed the interaction between risk assessment, case specific monitoring (CSM) of identified risks and general surveillance (GS) for unanticipated risks as envisaged in current EU regulations. Differences in approaches were being advocated by various groups in Europe reflecting the confusion over whether monitoring is a risk assessment or risk management tool. Some groups were advocating that both CSM and GS should be focused, hypothesis based monitoring to provide more risk information, with little distinction between them. They advocate developing lists of species to be monitored independent of the results of the initial environmental risk assessment (ERA). This is in contrast with the sentiments of the EC directive 2001/18 and the proposals for monitoring from EFSA (Sweet, 2006), which clearly indicate that CSM should be based on the findings of the ERA while GS should be monitoring for unanticipated adverse effects. Thus GS should not focus studies on particular features, but observe any environmental changes that may be associated with GMOs and determine whether they are adverse. There is general agreement that monitoring should focus on the environment in which the GM crop is being grown and that parameters associated with environmental protection goals should be monitored for any adverse indications. Those closest to the crop and most likely to see changes will be farmers growing the GM crops, agronomists working with several GM farmers and surveys being conducted on farms for agricultural or environmental reasons. Observations by these parties should be followed up with more in-depth investigations if adverse effects are suspected. This approach, while being precautionary, is not watertight and there are concerns that longer term or cumulative effects may not be detected until after significant damage has occurred. While trying to plug all possible gaps is the desire, in practical reality learning will only occur through experience of unanticipated effects. Hopefully the European monitoring model will allow us to experience, learn and intervene in a timely manner.

The presentations by Kerstin Schmidt and Detlef Bartsch demonstrated that this approach is both feasible and practical. General surveillance requires the collection of a diverse range of observational data from a number of different sources. Questions arise over what should be monitored, what data should be collected and how should they be analysed. One appropriate method identified by EFSA for collecting such data is for biotech companies to organize farmers to record data and submit them to the companies. Kerstin Schmidt and her co-authors developed farm questionnaires which asked farmers and/or agronomists to supply information on the cultivation and performance of GM crops and any impacts on farming systems. They conducted a research programme to test farmers' responses to these questionnaires to evaluate the viability and reliability of this monitoring system. Generally farmers responded well and submitted reliable data and observations which could be compiled, analysed and evaluated for any unintended effects. This study can now 
be used by biotech companies and competent authorities in Europe as an example of how such questionnaires should be constructed and implemented, and how data collected can be used to inform regulators and others.

Maize MON810 was approved for cultivation in the EU under the older regulatory system which did not include a requirement for post market environmental monitoring. Due to concerns in Germany that this GM maize should be cultivated in compliance with the newer Directive EC2001/18, a programme of post-market monitoring has been implemented by the Federal Office of Consumer Protection and Food Safety (BVL) in conjunction with Monsanto. Detlef Bartsch described the General Surveillance (GS) programme that has been put in place which included using existing environmental and agronomic monitoring systems as well as establishing farm questionnaires. BVL evaluated this approach to GS including the sources of monitoring information, the methods of collection of data and the analysis of the data. They concluded that, while some improvements were desirable, the general scheme was workable and effective. This bodes well for the future development of post-market environmental monitoring for a wider range of GM crops within the EU.

\section{Conclusions and discussion}

These last two papers showed that the General Surveillance system advocated in Europe is both feasible and practical when applied to a limited number of GM crops and releases. In future a wider range of GM crops will be grown more extensively in Europe, often in rotation or association with each other and containing both stacked and single events. In addition cultivation of GM crops will lead to changes in pesticide usage and other agronomic practices. Monitoring will become more complex and there will be problems associated with scale, separation of effects from different events, and separating direct GM effects from other changes occurring in farming systems. Existing farm monitoring programmes have shown that changes in farm crops and practices influence biodiversity generally through habitat and food chain effects. Instead of imposing specific monitoring programmes for each GM crop, it would seem more realistic that the receiving environments are monitored for any unanticipated adverse environmental effects. This should be done as part of general monitoring of all new technologies for their impacts on biodiversity and protection goals. Future land management should consist of the use of sustainable systems designed to meet environmental targets and monitoring to test the efficacy of these systems.

Case specific monitoring of GM crops for effects anticipated from the ERA will remain as a distinct and separate requirement, and will be hypothesis based and experimentally designed and analysed, as described by Gary Fitt for Bt-cotton in Australia.

\section{ACKNOWLEDGEMENTS}

The International Society for Biosafety Research acknowledges the many colleagues in New Zealand and Australia, their organisations and the sponsors for providing an excellent symposium in Wellington, NZ. The individuals and organisations were many and are detailed on the web site for the symposium: http://www.isbgmo. info/assets_/isbgmo_symposium

\section{REFERENCES}

Abel PP, Nelson RS, De B, Hoffmann N, Rogers SG, Fraley RT, Beachy RN (1986) Delay of disease development in transgenic plants that express the tobacco mosaic virus coat protein gene. Science 232: 738-743

Bais HP, Weir TL, Perry LG, Gilroy S, Vivanco JM (2006) The role of root exudates in rhizosphere interactions with plants and other organisms. Ann. Rev. Plant Biol. 57: 234-266

Balázs E, Petrik K, Gell G, Divéki Z (2008) Recombination studies of maize dwarf mosaic potyvirus (MDMV) as an important factor for risk assessment in maize plants. 10th International Symposium on the Biosafety of Genetically Modified Organisms, Wellington, November 16-21, 2008, Symposium Handbook, 128 p

Baumgarte S, Tebbe CC (2005) Field studies on the environmental fate of the Cry1 Ab Bt toxin produced by transgenic maize (MON810) and its effect on bacterial communities in the maize rhizosphere. Mol. Ecol. 14: 2539-2551

Birch ANE, Griffiths BS, Caul S, Thompson J, Heckman LH, Krogh PH, Cortet J (2007) The role of laboratory, glasshouse and field scale experiments in understanding the interactions between genetically modified crops and soil ecosystems: A review of the ECOGEN project. Pedobiologia 51: $251-260$

Brimecombe MJ, De Leij FA, Lynch JM (2001) The effect of root exudates on rhizosphere microbial populations. In Pinton R, Varanini Z, Nannipieri P, eds, The rhizosphere, Marcel Dekker, Inc., New York, pp 95-140

Broeckling CD, Broz AK, Bergelson J, Manter DK, Vivanco JM (2008) Root exudates regulate soil fungal community composition and diversity. Appl. Environ. Microbiol. 74: 738-744

Christeller JT, Markwick NP, Poulton J, O'Callaghan M (2006) Binding of an insecticidal transgene product to soil: biological activity of soil-bound avidin and the effects of time and microbial activity. Soil Biol. Biochem. 38: 2043-2052 
Demanèche S, Sanguin H, Poté J, Navarro E, Bernillon D, Mavingui P, Wildi W, Vogel TM, Simonet P (2008) Antibiotic resistance soil bacteria in transgenic plant fields. Proc. Natl. Acad. Sci. USA 105: 3957-3962

Dunfield KE, Germida JJ (2003) Seasonal changes in the rhizosphere microbial communities associated with field grown genetically modified canola (Brassica napus). Appl. Environ. Microbiol. 69: 3710-3718

Dunfield KE, Germida JJ (2004) Impact of genetically modified crops on soil and plant associated microbial communities. J. Env. Qual. 33: 806-815

EFSA (2009) Guidance for the risk assessment of genetically modified plants used for non-food or non-feed purposes. EFSA 2009, Parma

Godfree RC, Thrall PH, Young AG (2007) Enemy release after introduction of disease-resistant genotypes into plant-pathogen systems. Proc. Natl. Acad. Sci. USA 104: $2756-2760$

Gonsalves D (2003) Commercialization of transgenic papaya: Weighing benefits and potential risks. In Lelley T, Balázs E, Tepfer M, eds, Ecological Impact of GMO Dissemination in Agro-ecosystems, Facultas Verlags Wien, pp 131-137

Gulden RH, Lerat S, Blackshaw RE, Powell JR, Levy-Booth D, Dunfield KE, Trevors JT, Pauls KP, Klironomos JN, Swanton CJ (2008) Factors affecting the presence and persistence of plant DNA in the soil environment in corn and soybean rotations. Weed Sci. 56: 767-774

Head G, Surber JB, Watson JA, Martin JW, Duan JJ (2002) No detection of Cry1Ac protein in soil after multiple years of transgenic Bt cotton (Bollgard) use. Environ. Entomol. 31: $30-36$

Icoz I, Stotzky G (2008) Fate and effects of insect-resistant Bt crops in soil ecosystems. Soil Biol. Biochem. 40: 559-586

Kowalchuk GA, Bruinsma M, van Veen JA (2003) Assessing responses of soil microorganisms to GM plants. Trends Ecol. Evol. 18: 403-410

Levy-Booth DJ, Campbell RG, Gulden RH, Hart MH, Powell JR, Klironomos JN, Pauls KP, Swanton CL, Trevors JT, Dunfield KE (2007) Cycling of extracellular DNA in the soil environment. Soil Biol. Biochem. 39: 2977-2991

Levy-Booth DJ, Campbell RG, Gulden RH, Hart MH, Powell JR, Klironomos JN, Pauls KP, Swanton CL, Trevors JT, Dunfield KE (2008) Real-time polymerase chain reaction monitoring of recombinant DNA entry into soil from decomposing Roundup Ready ${ }^{\circledR}$ leaf biomass. JAFC 56: $6339-6347$

Marvier M, McCreedy C, Regetz J, Karieva P (2007) A meta-analysis of effects of Bt cotton and maize on non target invertebrates. Science 316: 1475-1477

Neumann G, Römheld V (2001) The release of root exudates as affected by the plant's physiological status. In Pinton
R, Varanini Z, Nannipieri P, eds, The rhizosphere, Marcel Dekker, Inc., New York, pp 41-93

Nickson T (2008) Planning environmental risk assessment for genetically modified crops: Problem formulation for stresstolerant crops. Plant Physiol. 147: 494-502

O'Callaghan M, Glare TR, Burgess EPJ, Malone LA (2005) Effects of plants genetically modified for insect resistance on non-target organisms. Ann. Rev. Entomol. 50: 271-292

O'Callaghan M, Brownbridge M, Stilwell W, Gerard EM, Burgess EPJ, Barraclough EI, Christeller JT (2007) Effects of tobacco genetically modified to express the protease inhibitor BSTI on non-target soil organisms. Environ. Biosafety Res. 6: 183-195

O'Callaghan M, Gerard EM, Bell NL, Waipara NW, Aalders LT, Baird DB, Conner AJ (2008) Bacterial and fungal communities associated with potatoes genetically modified to express the antimicrobial peptide magainin. Soil Biol. Biochem. 40: 1446-1459

Powell J, Levy-Booth D, Gulden R, Asbil WL, Campbell RG, Dunfield KE, Hamill AS, Hart M, Lerat S, Nurse RE, Pauls PP, Sikkema PH, Swanton CJ, Trevors J, Klironomos J (2009) Variety and management effects on soil food web dynamics and litter decomposition in a geneticallymodified, herbicide-tolerant cropping system. J. Appl. Ecol. 46: $388-396$

Raaijmakers JM, Paulitz CT, Steinberg C, Alabouvette C, Moënne-Loccoz Y (2009) The rhizosphere: a playground and battlefield for soilborne pathogens and beneficial microorganisms. Plant Soil 321: 341-361

Raybould A (2007) Ecological versus ecotoxicological methods for assessing the environmental risks of transgenic crops. Plant Sci. 173: 589-602

Singh BK, Milard P, Whitely AS, Murrell JC (2004) Unravelling rhizosphere-microbial interactions: opportunities and limitations. Trends Microbiol. 12: 386-393

Sørensen J (1997) The rhizosphere as a habitat for soil microorganisms. In van Elsas JD, Trevors JT, Wellington EMH, eds, Modern soil microbiology, Marcel Dekker, Inc., New York, pp 21-45

Sweet JB (2006) Integrated Approaches to General Surveillance. Journal für Verbraucherschutz und Lebensmittelsicherheit (Journal of Consumer Protection and Food Safety) 1, Supplement 1: 49-50

Tapp H, Stotzky G (1995) Insecticidal activity of the toxins from Bacillus thuringiensis susbspecies kurstaki and tenebrionis adsorbed and bound on pure and soil clays. Appl. Environ. Microbiol. 61: 1786-1790

Tapp H, Stotzky G (1998) Persistence of the insecticidal toxin from Bacillus thuringiensis subsp. kurstaki in soil. Soil Biol. Biochem. 30: 471-476

Tepfer M (2002) Risk assessment of virus-resistant transgenic plants. Ann. Rev. Phytopath. 40: 467-491 
Tepfer M, Balázs E (eds) (1997) Virus-resistant Transgenic Plants: Potential Ecological Impact. Springer Verlag, BerlinHeidelberg-New York

Weinert N, Meincke R, Gottwald C, Heuer H, Gomes NC, Schloter M, Berg G, Smalla K (2009a) Rhizosphere communities of genetically modified zeaxanthin-accumulating potato plants and their parent cultivar differ less than those of different potato cultivars. Appl. Environ. Microbiol. 75: 3859-3865
Weinert N, Meincke R, Gottwald C, Radl V, Dong X, Schloter M, Berg G, Smalla K (2009b) Effects of genetically modified potatoes with increased zeaxanthin content on the abundance and diversity of rhizobacteria with in vitro antagonistic activity do not exceed natural variability among cultivars. Plant Soil, DOI: 10.1007/s11104-009-0024-z

Zwahlen C, Hilbeck A, Gugerli P, Nentwig W (2003) Degradation of the Cry1 Ab protein within transgenic Bacillus thuringiensis corn tissue in the field. Mol. Ecol. 12: 765-775 